\title{
The Development, Technique and Application of Ready-Made in the Product Design
}

\author{
Ching-Yi Wang \\ Department of Creative Product Design, Asia University, Taiwan \\ Email: catincar@gmail.com
}

Received 6 March 2015; accepted 23 April 2015; published 29 April 2015

Copyright (C) 2015 by author and Scientific Research Publishing Inc.

This work is licensed under the Creative Commons Attribution International License (CC BY).

http://creativecommons.org/licenses/by/4.0/

(c) (i) Open Access

\begin{abstract}
The purpose of this study was examined how people respond to variations in artistic ready-made products and what key features induce in the design cognition processes. In the competitive environment of consumer products, continuing to create new products is the only way to meet the consumers' rapidly preference changing. Ready-made might be proving a chance to inspire the creative design concept for developing a new product design. In the experiment, this study first analyzes Ready-made design products to compare differences in form and content. Next, a card sorting experiment with Ready-made product designs as samples is implemented. The reactions of participants are observed using grounded theory analysis. Following the coding process, axial coding can be divided into five characters: 1) selecting components, 2) extracting function, 3) editing technique, 4) forming perception, and 5) interpreting meaning. Finally, taking the selection component as the core category, selective coding is used to address the degree of borrowing of objects and the process of construction.
\end{abstract}

\section{Keywords}

Ready-Made Design, Case Studies, Perception, Design Process, Grounded Theory

\section{Introduction}

Most of the works created by the Droog of the Netherlands, which are made from scrap heaps (Ramakers, 2006), are typical examples of ready-made design. Such works include a long bench made by inserting old chairs back into a Treetrunk (Figure 1) and a chest of drawers composed of drawers that cannot be put on top of each other (Figure 2). These works are fascinating and unbelievable, even confusing, but at the same time trigger warmth 


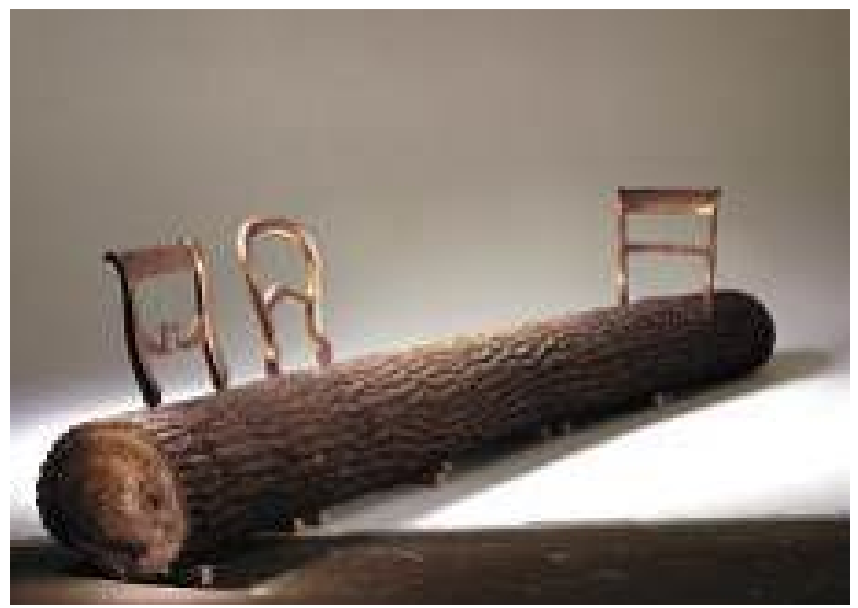

Figure 1. Treetrunk bench.

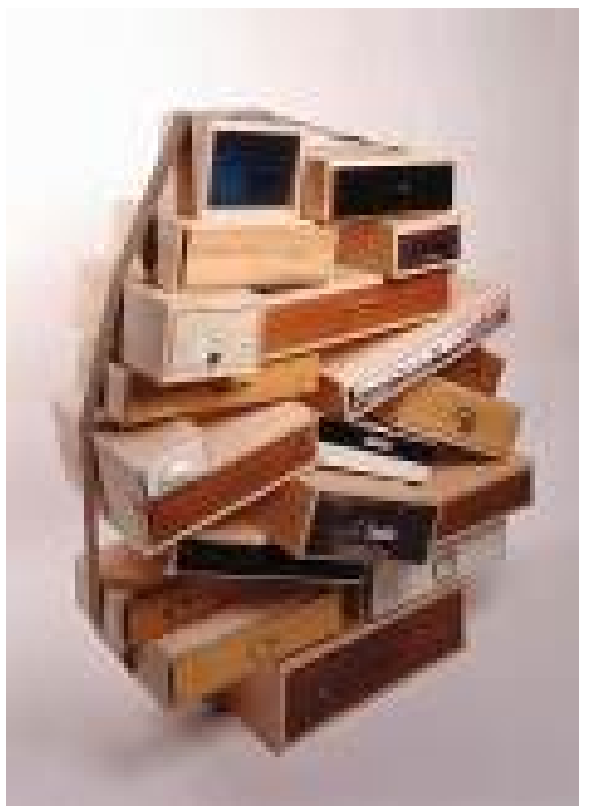

Figure 2. Chest of drawers.

and a faint sense of familiarity. Rather than manufacturing general consumer goods, these designs are aimed at transforming old objects into artwork by means of experimentation, distortion and reconstruction and establishing new value identification using the appeal of emotion or image. This study systemizes and introduces the thinking and skills of these creators from the perspective of literature and then analyzes in detail the characteristics of composition of ready-made design with regard to concepts in design creation, such that designers can create more innovative ideas on the frontier of design development.

In the field of industrial design, ready-made design can be traced to the works of Achille Castiglioni (19182002), an Italian designer in the 1950s, such as Sella Stool (Figure 3). The inspiration of using a bicycle cushion as a chair cushion (Lin et al., 2006) was derived from the fact that he liked sitting and fidgeting while making telephone calls. French architect Francois Burkhardt commented, Achille changes the function of daily products, introduces the components into different context, and endows a meaning instinct from the original function, thus exploring the unexpected conversion between components in a fun fashion (Taki, 2004). He moved the components away from their original context and put them in a new context, thereby creating products that integrate function and appearance. Toio Uplighter (Figure 4) is a floor lamp composed of a fishing pole and car lamp. Mezzadro Stool (Figure 5) is a bench constructed from disassembling the ready-made seats of a farm cultivator. 


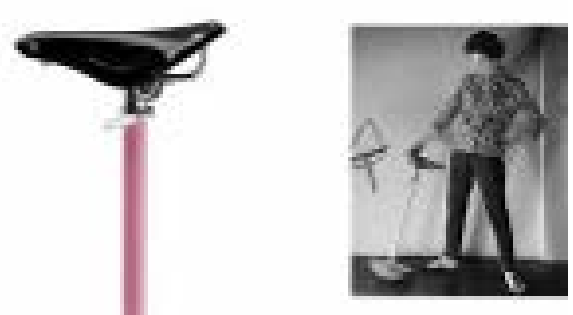

Figure 3. Sella stool.

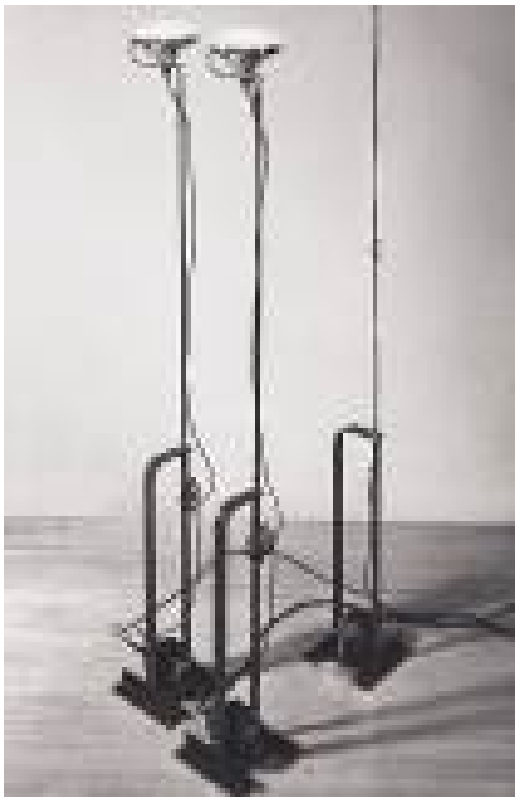

Figure 4. Toio uplighter.

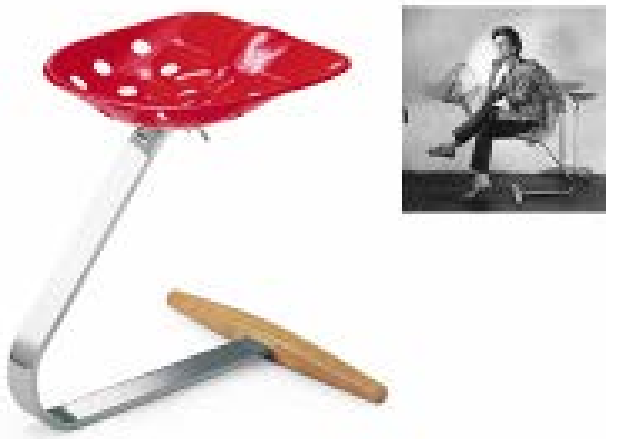

Figure 5. Mezzadro stool. 
In the 1980s, Ron Arad (1951-) was enormously influenced by Duchamp. His work Rover Chair (Figure 6) was first conceived considering low costs and comfort, which was achieved by using cushions of scraped cars. However, the stools were not manufactured in large quantities as a result of insufficient materials (Sudjic, 1989). Similarly, Puch Stool (Figure 7) was made by installing the chair cushions of bicycles on a metal shelf in the shape of pyramid, significantly resembling the Sella Stool.

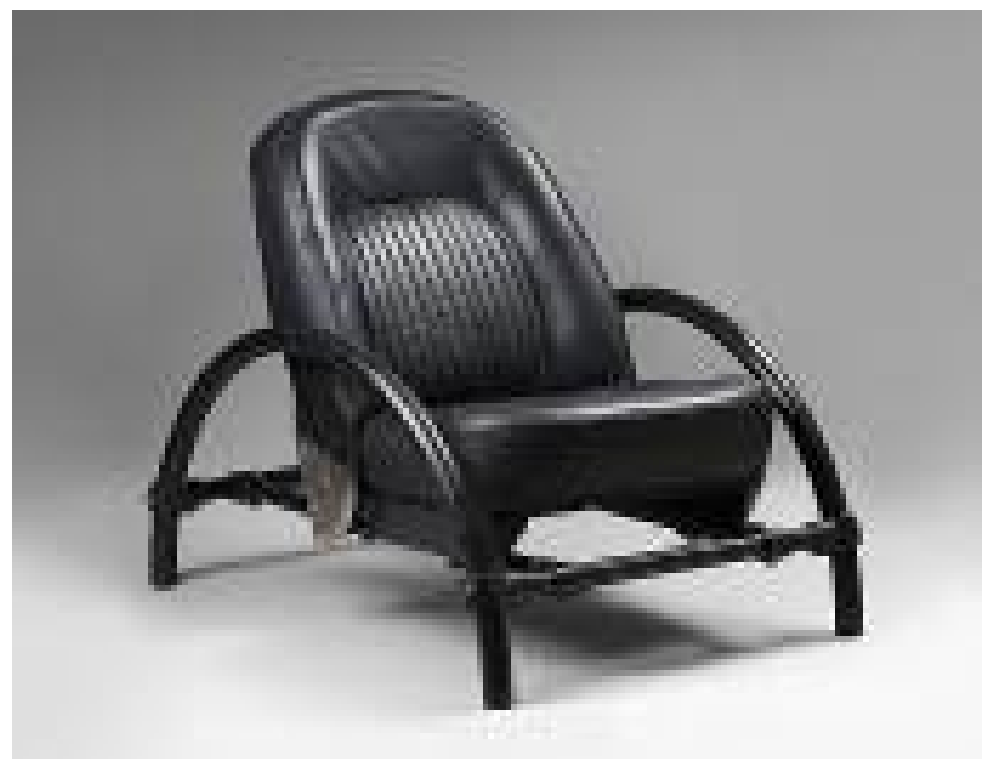

Figure 6. Rover chair.

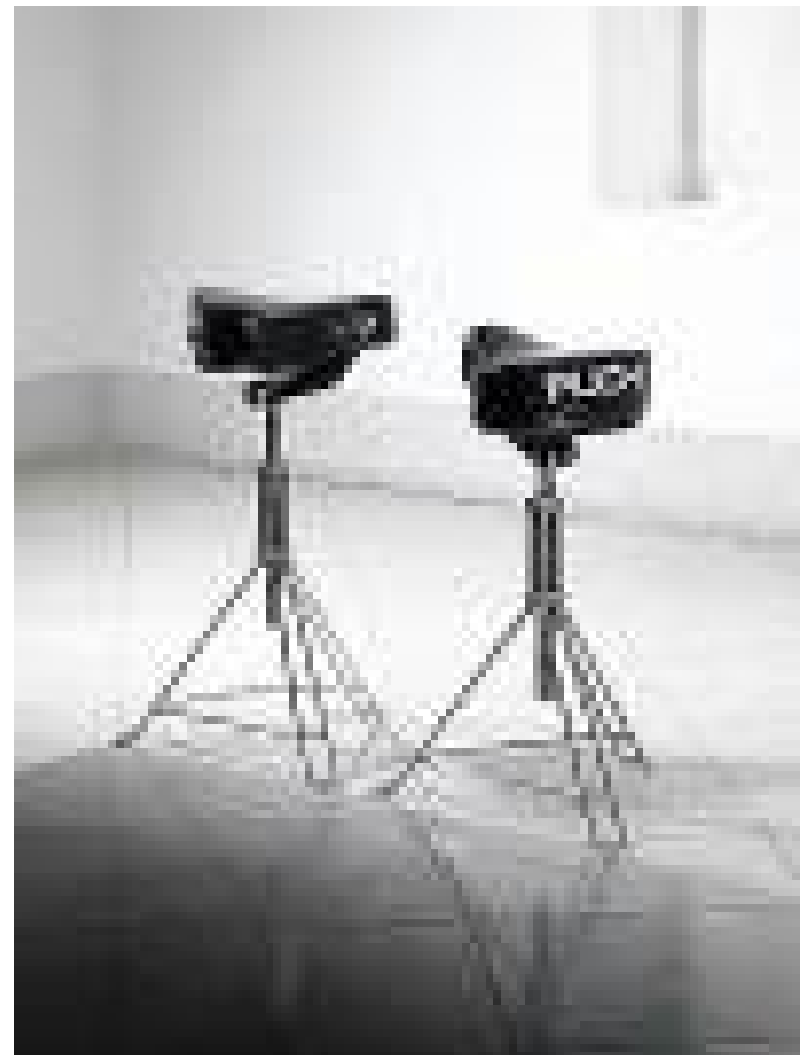

Figure 7. Puch stool. 
In the 1990s, Droog Design, which was founded in Amsterdam, Holland, often created works by recycling daily commodities. For example, the Treetrunk Bench (Figure 1) by Jurgen Bey (1965-) was made by inserting an old chair back into long tree trunks, whereas Kokon Furniture (Figure 8) was made by coating a layer of flexible PVC material on the surface of furniture by means of the spider-web technique to maintain the appearance of the exterior outline. Lamp Shade Shade (Figure 9) was made by covering shade that reflected light on the outside of a lamp modeled after an antique. When the lamp is on, the complicated details of the classical light fixture can be observed. When the lamp is off, a dark cylinder that reflects light enters into sight, which makes the works a concise modern design. The Milkbottle Lamp (Figure 10) by Tejo Remy (1960-), another Droog designer, was made by installing a lamp inside a recycled empty milk bottle. The appearance of the box triggers people's memory. Another famous work, Chest of Drawers (Figure 2), was made by binding the secondhand drawers taken from scraped furniture with strings. The feature and memory of each drawer are emphasized, so this work is also called You Can't Lay Down Your Memories. Unlike ready-made art works, Droog’s works exhibited a sense of art and retained the basic function of the commodities at the same time. The ancient and innovative appearance displays enlightening ideas and associations, making common goods relatively interesting.

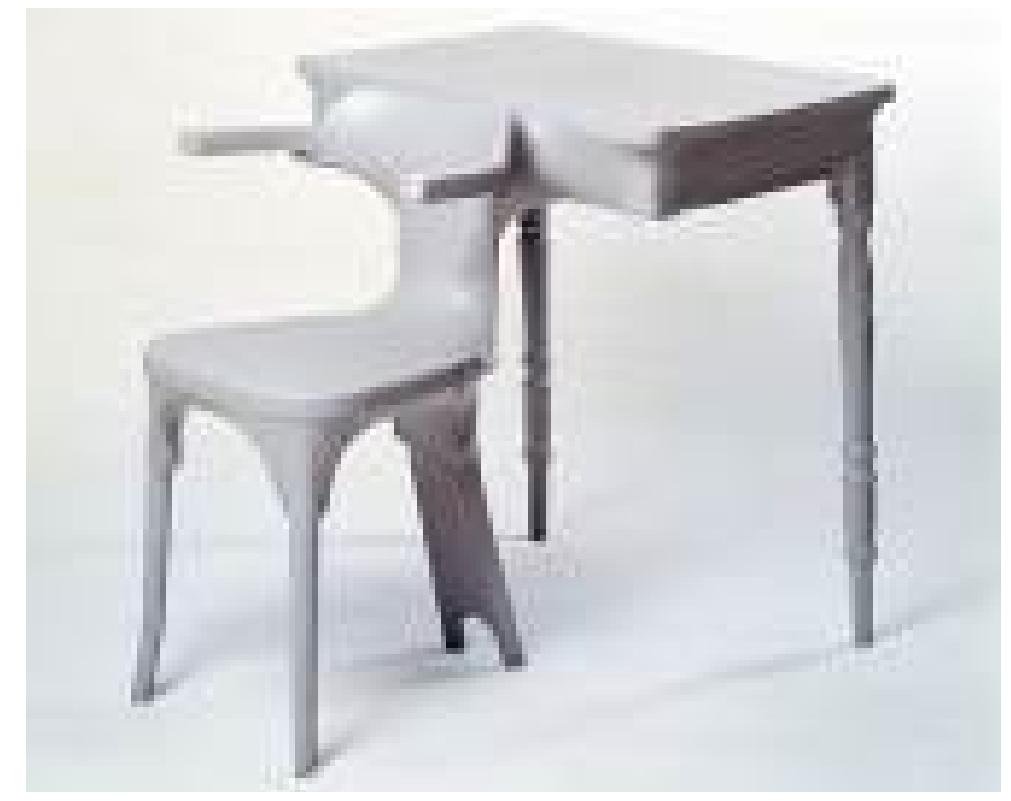

Figure 8. Kokon furniture "table-chair”.

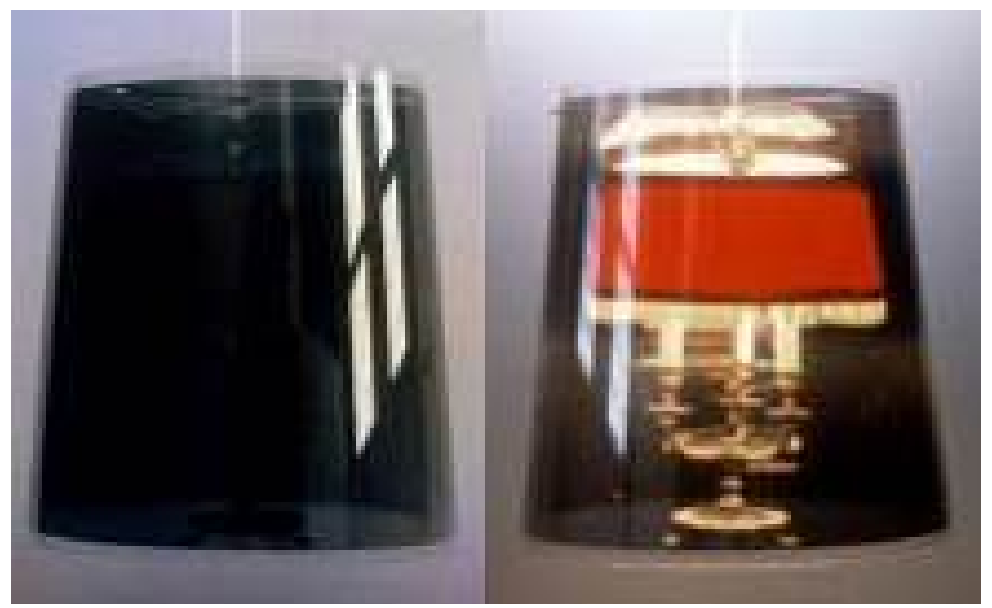

Figure 9. Lamp shade shade. 


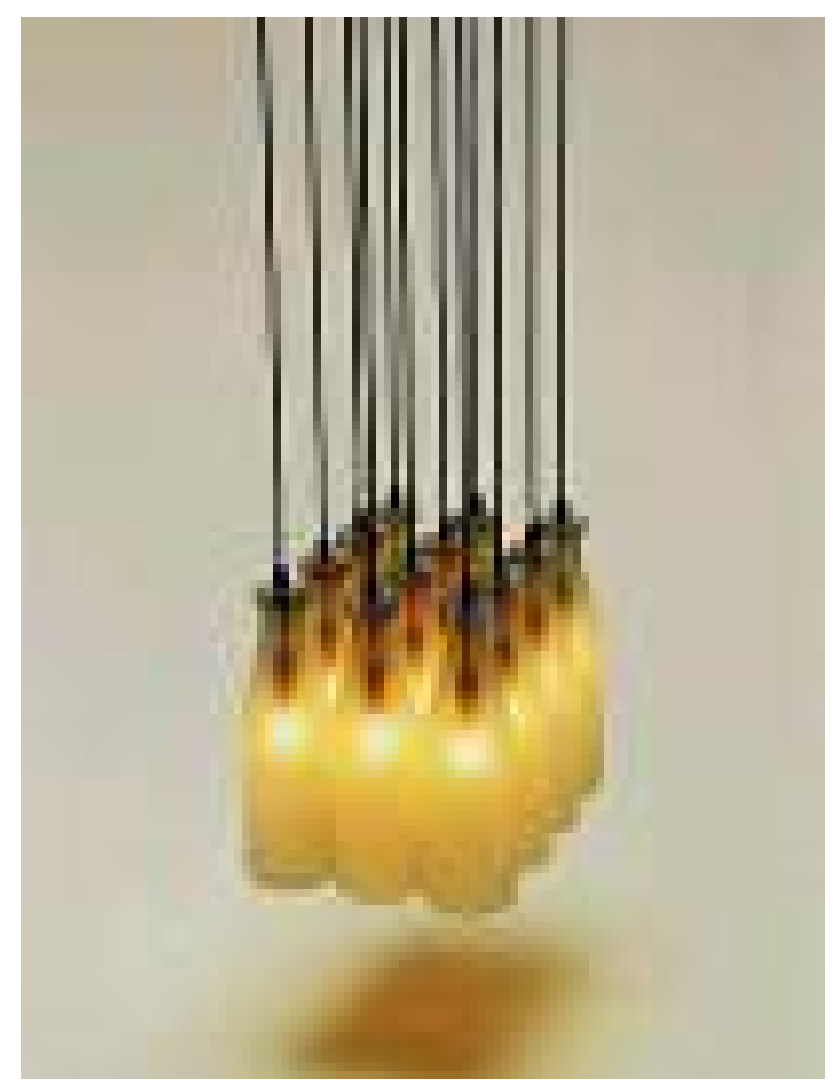

Figure 10. Milkbottle lamp.

In the work Ecolo Vase (see Figure 11), Italian designer Enzo Mari (1932-) cut ready-made plastic bottles in a simple way to create the image of a vase, escaping the standards of product design and manufacturing. British designer Jasper Morrison (1959-) commented, Most designers, after analyzing the problems, find systematic design within limited sphere, which is the relatively traditional solution. However, Mari's design expresses certain poetic sense and humanity in the original and strong attitude (Rawsthorn, 2008). Mari's design is based not on innovation but on the satisfaction of basic needs and representation of humanistic thinking after repeated thinking. In the exhibition The Intellectual Work: Sixty Paperweights (Figure 12), which was held in Berlin in 2011, he presented 60 pieces of paperweight made using scraped industrial products, such as faucets, doorknobs, metal contacts, and scraped glass. He deemed that the essence of creation is to make smarter works than anyone else.

The Brazilian Campana brothers transformed garbage and industrial waste. For example, Trans...Chair (Figure 13) was made using vines covering plastic things. They state that Brazil has a very chaotic side, but it's not chaos in a negative sense. It's chaos that's happiness, like the carnival. At the same time it's very flamboyant, organic, and Brazil is a baroque country (Fernando \& Humberto, 2010). Their works are different from Droog Design because they not only arouse criticisms of design situations in real life but also combine the affection of Brazilians for their country. However, it is not comfortable to use; the design goes completely against the design principles of comfort, pragmatism and aesthetics, creating contradiction and conflict between function and visual sense. That their work sticks to design concepts such as a sense of fun, joy and emotion but not function should be emphasized (Hong, 2009). In Bitter Lemon Light (Figure 14), by German lamp and lantern designer Ingo Maurer (1932-), the classical work Juicy Salif Lemon Squeezer by French designer Philippe Starck was used as the pedestal of a lamp, and a lemon lamp with claws was installed above to clamp the squeezer. In this way, the work, which was originally only used as part of a collection, is endowed with more practical Function in ironic and interesting ways (Fang et al., 2006).

Ready-made works are similar to experiencing the process from death to rebirth. Designers inject new soul into a dead product, revitalizing it and giving the product a second life. The new soul symbolizes the essence and connotation of the product, while the dead components still retain the borrowed appearance after the trans 


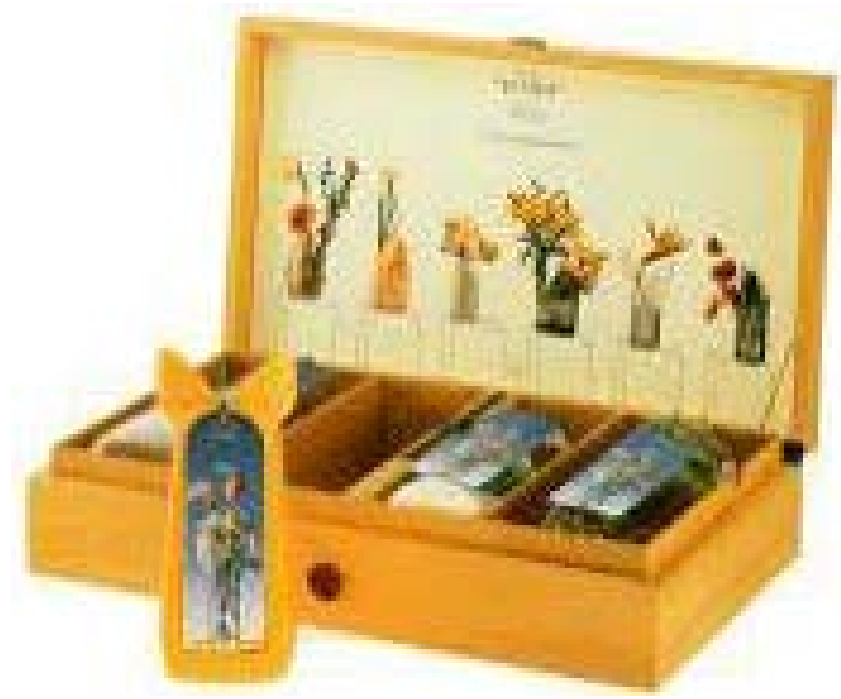

Figure 11. Ecolo Vase.

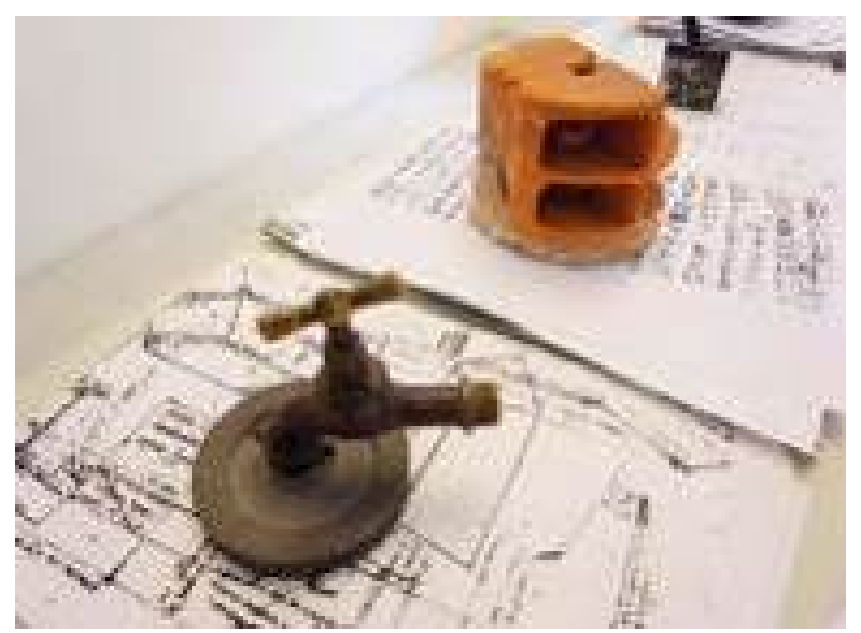

Figure 12. The intellectual work.

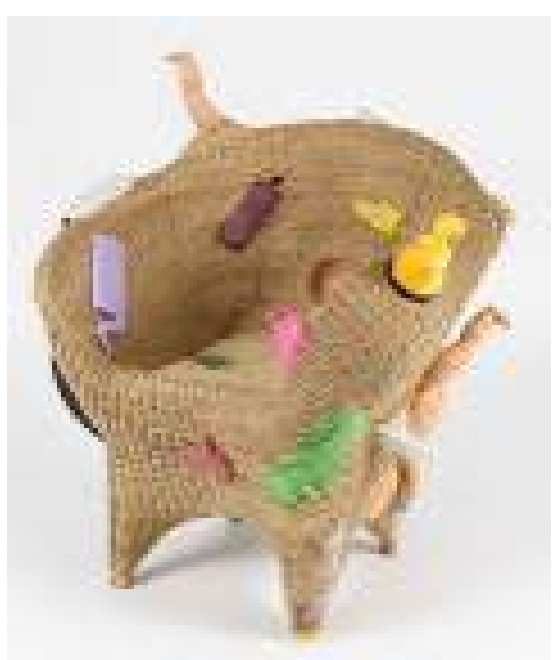

Figure 13. Trans...Chair. 


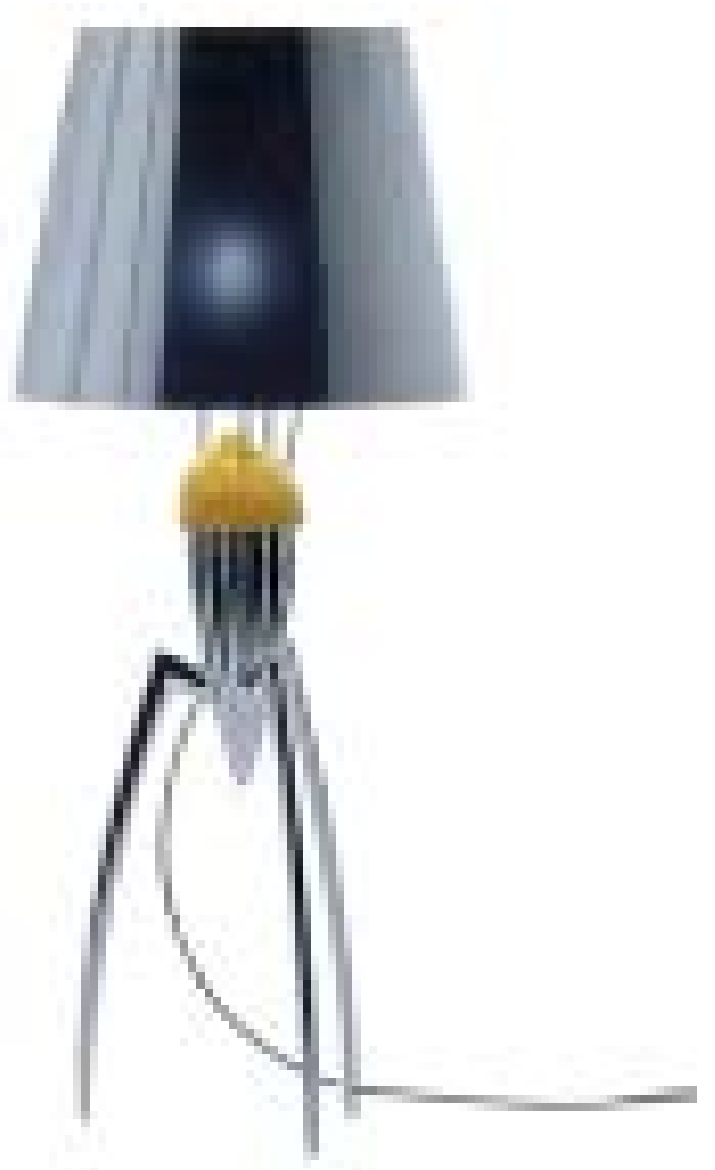

Figure 14. Bitter Lemon Light.

formation. In this way, the special rebirth process makes ready-made works a new entity with a memory of the past - a combination of the new and the old. This study intends to further explore the interesting process of rebirth and the messages and feelings conveyed to people.

This study is carried out in two stages. In the first stage, this study performs a literature review and explores and compares the works of designers' representations in art or product design based on the collected relevant theories and cases. The results are presented above. The second stage focuses on experiment; participants classify the ready-made products and describe the reasoning for the classifications in written form. In this experiment, card sorting and grounded theory are applied. Different from guided card sorting, in which participants classify according to different standards to reduce the number of groups, this experiment adopts an unconstrained sorting method in which participants can decide the number of classified groups according to any favored standard (Goodman et al., 2007). The card sorting in this experiment is aimed at investigating the opinion and cognition of participants towards ready-made products, so the number and categories of groups are not the emphasis. Therefore, during data analysis, grounded theory (Glaser \& Strauss, 1967; Strauss, 1991) is applied for oral analysis, as opposed to the hierarchical clustering method (Luo \& Lin, 2007; Hu \& Lin, 2008) that is frequently used in card sorting.

\section{Methods}

\subsection{Participants}

Forty undergraduate students in this study, of which twenty have design backgrounds (11 males, 9 females; mean age $=28 \mathrm{y})$ and twenty are novices without design backgrounds (10 males, 10 females; mean age $=23 \mathrm{y})$, from National Chiao Tung University were paid 150 New Taiwan Dollars to participate in the experiment. 


\subsection{Materials}

The stimuli included 246 colorful pictures of ready-made products on a white or black background. All of the selected pictures were acquired via the Internet and depicted works by famous designers such as Achille Castiglioni, Enzo Maurer, Ingo Maurer, Ron Arad, Arik Levy, Fernando and Humberto Campana, Jurgen Bey, Tejo Remy, Maurizio Lamponi Leopardi, Martino Gamper, David Olschewski, Andy Gregg and Katie Thompson. These pictures were selected from experts with more than ten years of experience in product design. The samples were then classified into 3 categories, namely 70 chairs, 98 lamps and 78 other, as samples for the test. All the samples were $10 \times 10 \mathrm{~cm}$ in size, and numbers were printed on the lower right corner for better identification (Figure 15).

\subsection{Procedure}

Participants classify all the samples based on the similarities between the samples as well as personal favor, subjective and instinctive ideas, into an unlimited number of groups and in unlimited time. Following the classification, the participants are asked to describe the reasons for the classifications in written form. The samples that fail to fall into any group will not be counted. Finally, the card number, which is created for classification and description data, will be filed.

\subsection{Data Collection and Analysis}

In this study, the subjective description data of every sample from the participants are coded by means of the nodes function of the qualitative software QSR NVivo 8, including Open Coding and Axial Coding (Glaser \& Strauss, 1967; Strauss, 1991). The first step is to conceptualize the original materials using Open Coding by Free Nodes of NVivo, decomposing the observed phenomenon in each section of sentences into concepts and then naming the particular phenomenon (in vivo principle). In the next procedure, the researcher performs Axial Coding using Tree Nodes in the software, connecting the relationships between various categories into a dendritic structure and naming the nodes in a higher level and in a more abstract fashion that covers all the concepts. The hierarchical relationship between the axial categories is presented with a triangle structure in three hierarchies. The researcher tried to quote the conceptual nouns in the relevant design argument in the naming process of the codes to continue acquisition from the literature review. In the coding process (Figure 16), this study concentrates on the analyzed data associated with the function and component of the ready-made objects.

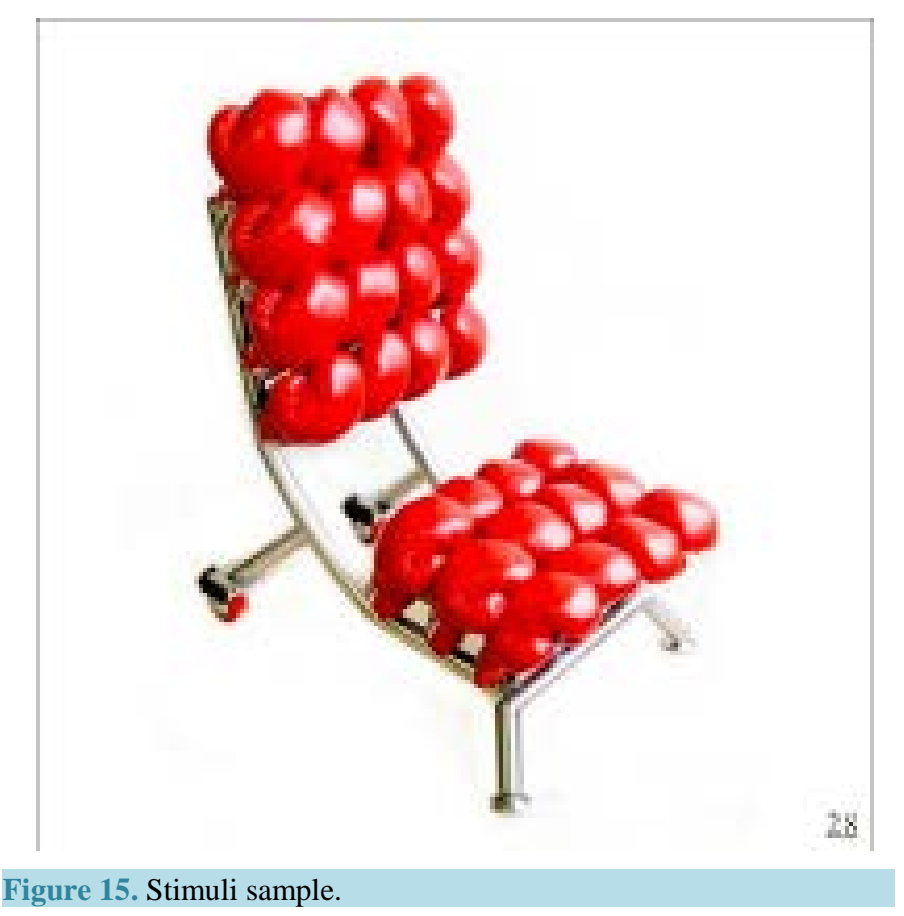




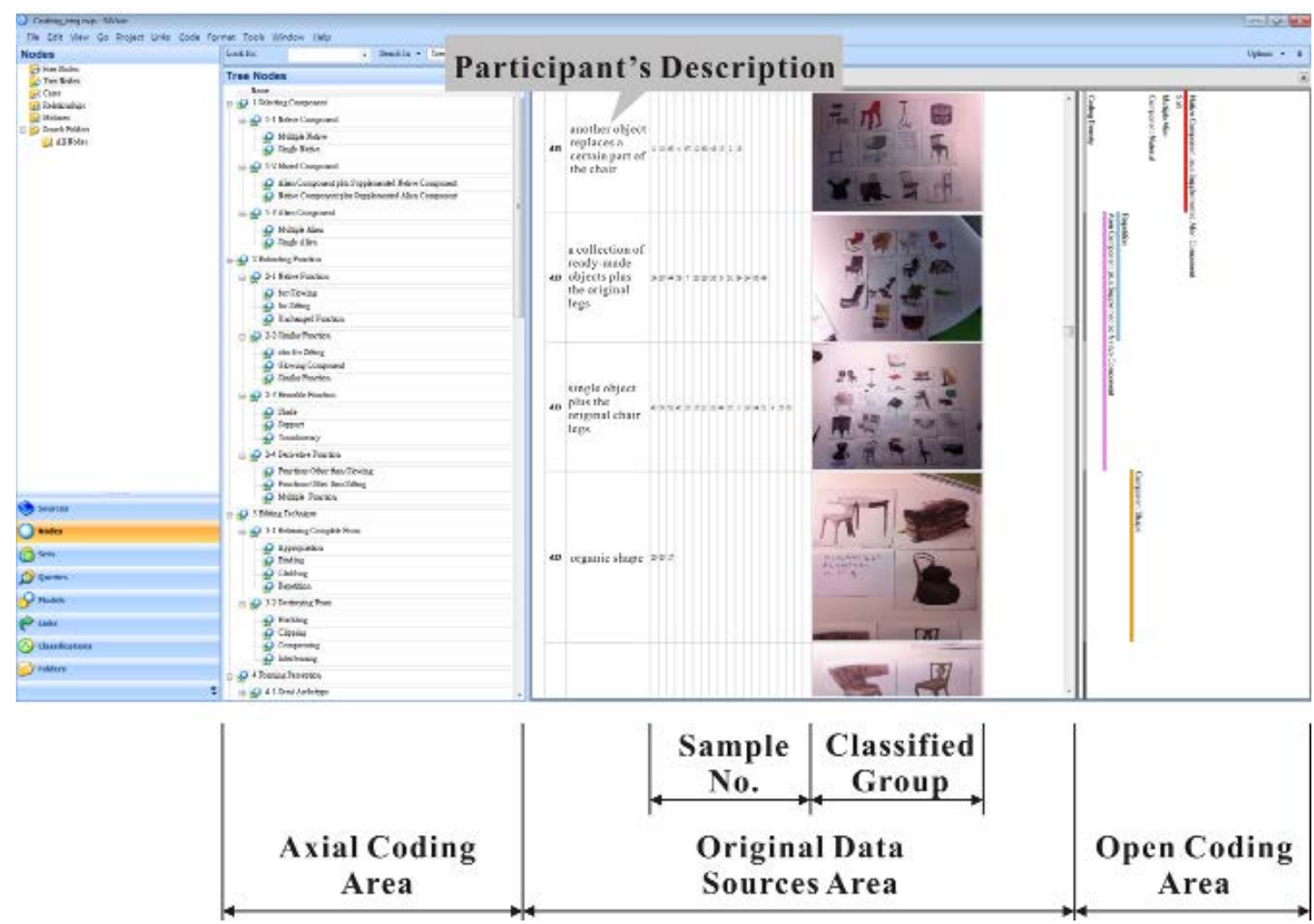

Figure 16. Data collection and analysis in QSR Nvivo 8.

\subsection{Representing Design Knowledge in Diagrams}

Using diagrams to model design knowledge in architectural design is nothing new. Idea association involves a dynamic linking process between ideas as well as between ideas and design cases (Lai, 2004). During the process of finding design ideas, designers often decompose a design into several architectural elements and features and use them as keys to link relevant ideas.

Figure 17 illustrates different line-types to express the detailed inter-relationships between the elements. Figure 17(a) shows the "Issue-Concept-Form" (ICF) structure created from (Oxman, 1994, 2004). The ICF schema illustrates the connection from a specific design issue to its corresponding design solution concept and the resulting design outcome form. It provides linkages across the three levels of Issue, Concept, and Form. The issue is related to the design task and offers the identification of particular points in design problems. The concept is the method of an opinion in relation to a design issue, and so it is an abstract form for solving design problems. The form is the specific design artifact that solidifies the concept. Using the building design as an example, the "light-opening-window" is used instead of these three levels.

Figure 17(b) displays the mind-mapping structure as design tools to present the overall results. Some researcher promotes a non-hierarchical network structure to represent the procedure of the design problem form as a series of linking issues and concepts (Kokotovich, 2008). The network structure makes the concept present the most complex form. Therefore, it can be helpful for the designer to understand the problem space and the interactive relationships among the design issues. In addition to connecting to elements at a major level or sub-level, the elements can also link between them at the same level. Moreover, the connections between the differential elements also define the interrelationships in detail.

Figure 17(c) shows the results of (Wong, 2010). The related concepts linking to the influencing forces extracted from the analyzed text in the open coding stage are organized into network structures, illustrating their connections, and then combined with selective coding into a hierarchical structure diagram to show the major categories and sub-categories of the forces influencing the case study. By contrast, the ICF and the non-hierarchical networks structures both seek to represent vertical relationships across the three levels. Some researcher 


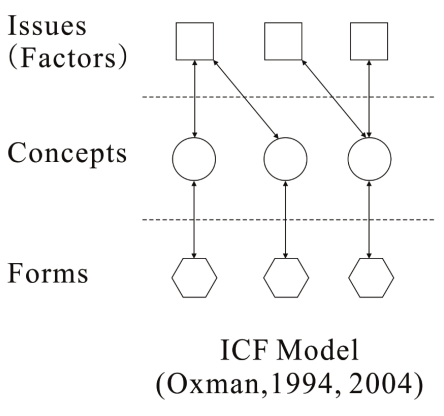

(a)

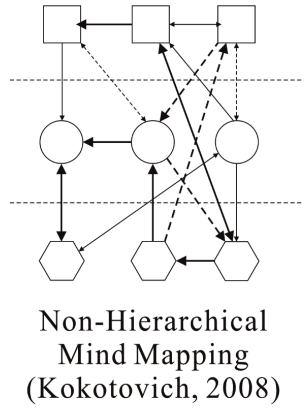

(b)

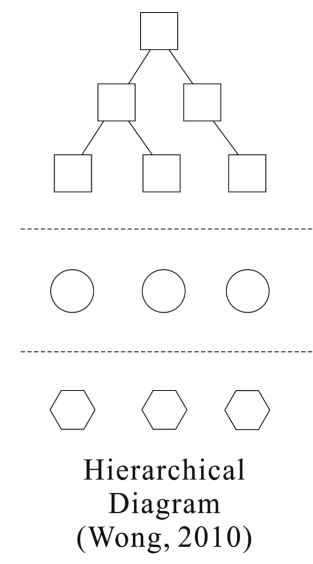

(c)

Figure 17. Comparison of linear ICF model, network non-hierarchical mind mapping and hierarchical diagram (Wong, 2010).

argues that the former two are useful for diagramming students and novice designers in education and the process of design, respectively (Wong, 2010), whereas the latter research uses diagramming as a method to examine the design process. In this study, the results of selective coding are combined into a horizontal diagram with a triangle structure (Cheng et al., 2010; Wong, 2010) to clearly show the inter-relationships between the major categories and sub-categories of the forces influencing ready-made objects.

\section{Results}

\subsection{Axial Coding}

The result show the completed 55 concepts $(48+7)$ from 1416 references, among which 48 effective concepts are classified into 18 sub-categories according to the relevance between the Tree Nodes and then classified into the following five major categories in descending order of the number of references: Selecting Components, Extracting Function, Editing Technique, Forming Perception, and Interpreting Meaning. These concepts are then categorized by drawing abstract coherence in the axial coding stage and organized into non-hierarchical network diagrams to represent all relevant concepts. A detailed explanation follows.

\subsubsection{Selecting Components}

The first axial category, Selecting Components, refers to the selection of components that can replace parts of the products, including Native Components, Mixed Components, composed of two types of components, and Alien Components; altogether, there are 468 nodes. A detailed breakdown of the number of nodes is shown in Figure 18.

The sub-category Native Components is the product of single or multiple original product components, including Single Native Component and Multiple Native Components, two nodes. The sub-category Mixed Components includes two nodes, Native Components plus Supplemental Alien Components and Alien Components plus Supplemental Native Components. With the former, Native Components are the major part, and some other parts are changed into alien components. By contrast, the latter is composed of single or multiple alien components plus several native components, with the alien components as the major part. The final sub-category, Alien Components, is the product of single or multiple components of other products, including Single Alien Component and Multiple Alien Components, two nodes.

\subsubsection{Extracting Function}

After selecting suitable components comes the second axial category, Extracting Function. In this stage, with affordance as the foundation, the researchers take into consideration physical properties such as usage, function, and size, selecting substituting components that can furnish virtual functions of the products to cater to the expected function and usage of the products. This category covers four sub-categories, Native Function, Similar 


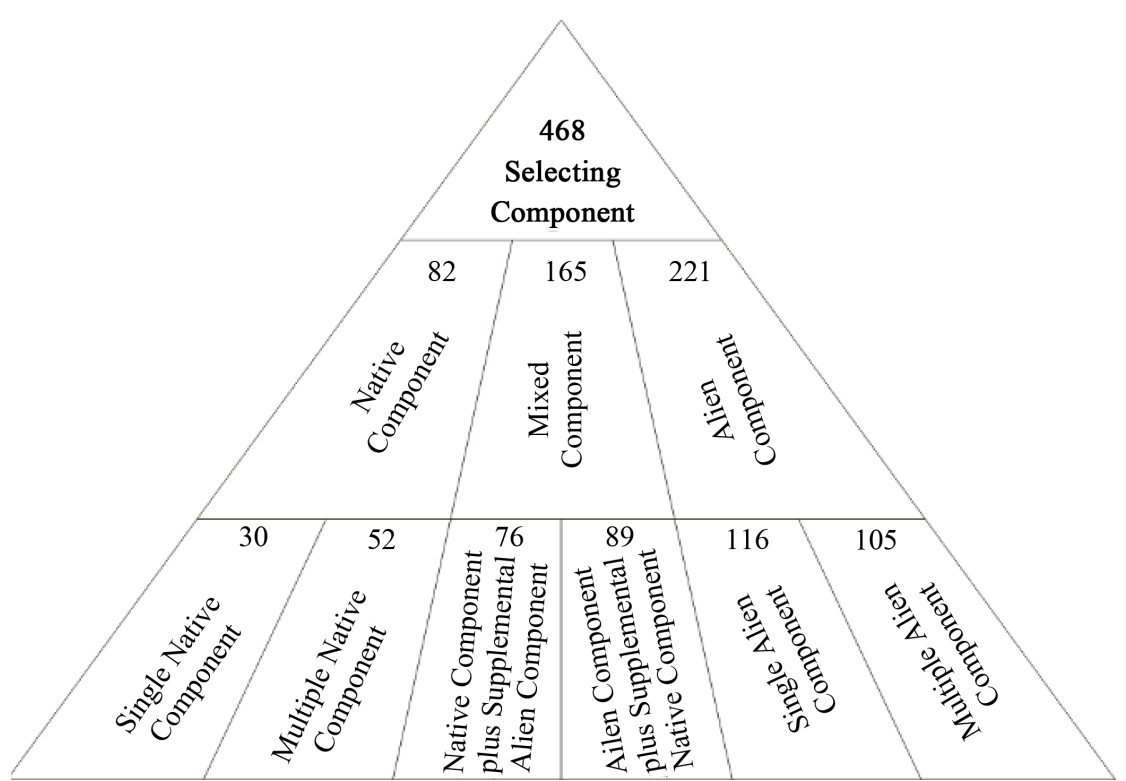

Figure 18. Main categories and sub-categories of Selecting Component factors in readymade design. (In the bottom layer are the Free Nodes of the opening coding; in the middle layer is the sub-category; in the top layer are the Tree Nodes of the Axial Coding. The number in each block is the number of the node references, which is the sum of the node number in the bottom layer and that in the middle layer. The representative sample figure of each category is shown below the picture. The calculation method of the node references of Figures 23-26 is the same as this figure).

Function, Bearable Function, and Derivative Function, with 158 nodes. The number of nodes in every sub-category is shown in detail in Figure 19.

The sub-category Native Function refers to using the component of the original products and retaining the old functions of the components and includes three nodes, namely for Sitting, for Glowing and Unchanged Function. The sub-category Similar Function refers to the fact that the affordance of the components is similar to the original function of the products and includes three nodes, namely also for Sitting, Glowing Component, and Similar Function. The sub-category Bearable Function refers to the components replacing the function of the original products, but still bringing into play the same type of function, and includes three nodes, namely, Support, Translucency, and Shade. The sub-category Derivative Function endows the products with the second function and includes three nodes, namely Functions Other than Sitting, Functions Other than Glowing, and Multiple Functions.

\subsubsection{Editing Technique}

The third axial category, Editing Technique, refers to the processing technique of the components, which makes recombining and forming the selected components possible after detachment. It covers two sub-category, Retaining Complete Form and Destroying Form, with the former simply combining the components to retain the complete form and the latter transforming the interior structure of the components to cater to the usage of the products. Altogether, there are 146 nodes. The number of nodes in subcategory is shown in detail in Figure 20.

The sub-category Retaining Complete Form covers four nodes, namely Appropriation, Repetition, Cladding, and Binding. The appropriation technique refers to a single component directly embodying the appearance of the product. The repetition technique refers to making a single product from multiple components to enhance the sense of beauty with visual strength. The cladding technique refers to covering new skin on the surface of the component to change the original material of the component. The binding technique combines a group of components into one using strings. The sub-category Destroying Form covers four nodes, namely Buckling, Intertwining, Clipping, and Compressing. The buckle technique involves twisting a component into various angles to create deformation or a twisting appearance for the component. The intertwining technique involves circling a component into one in the same direction. The clipping technique refers to cutting a component into particular 


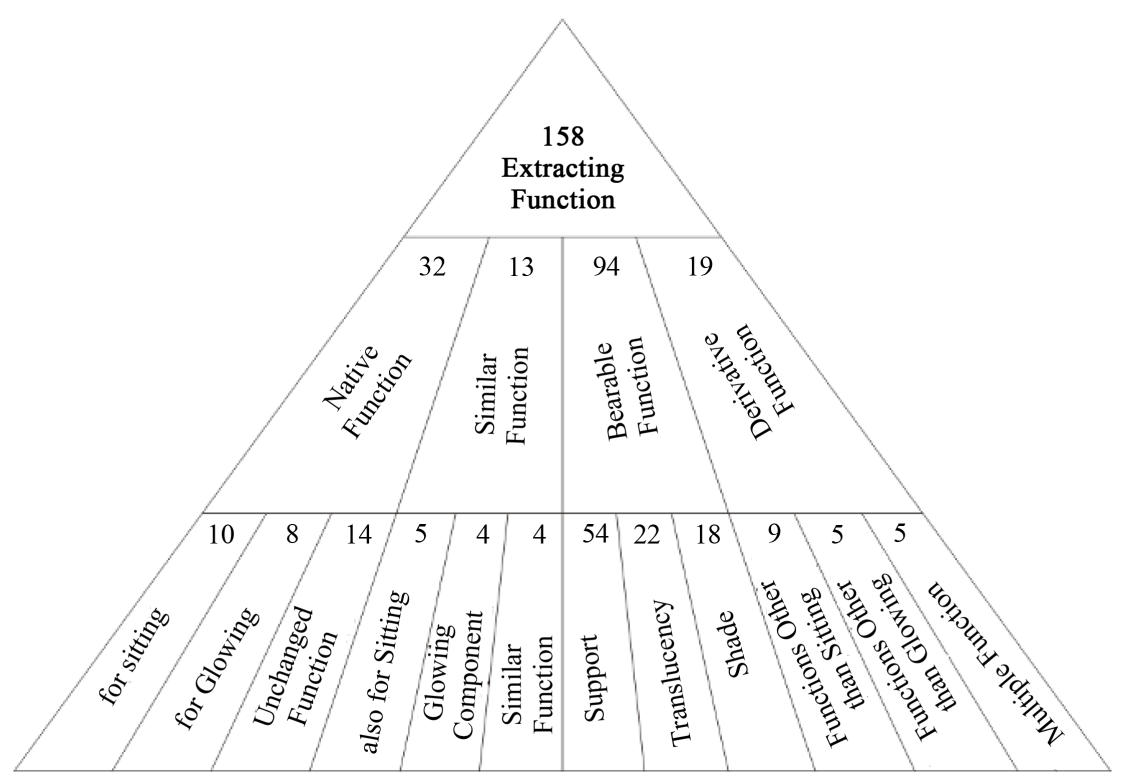

Figure 19. Main categories and sub-categories of Extracting Function factors in readymade design.

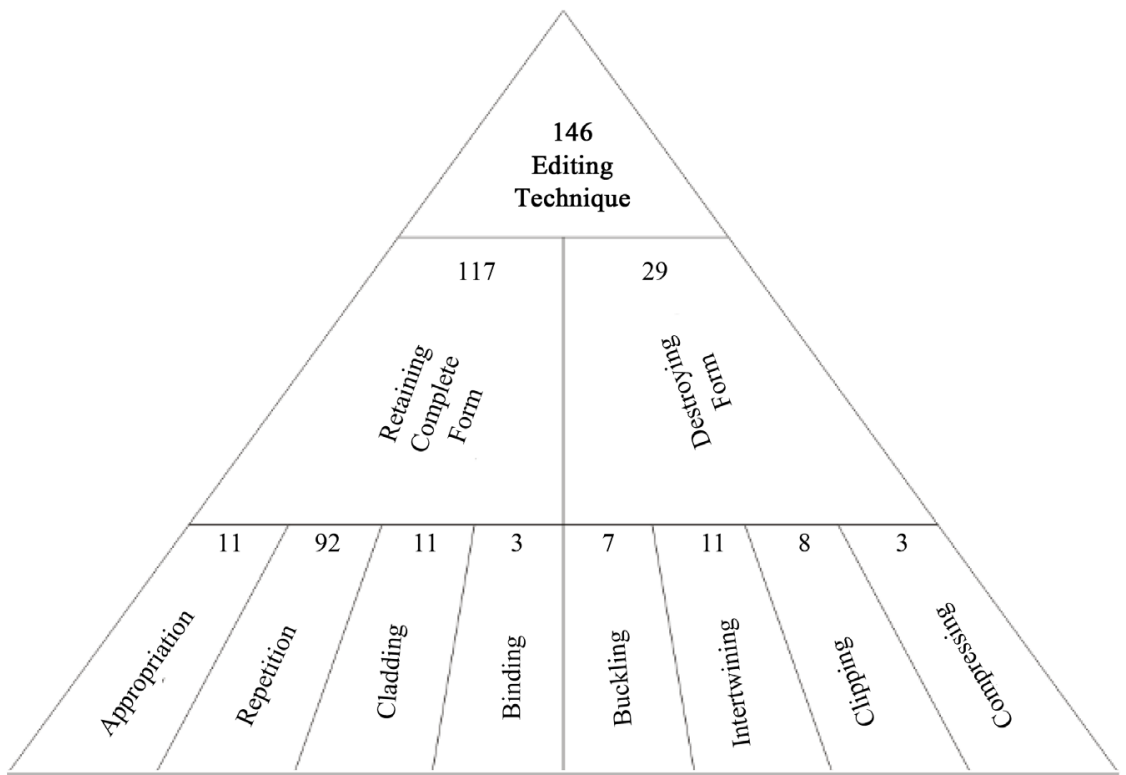

Figure 20. Main categories and sub-categories of Editing Technique factors in readymade design.

shapes or removing unused parts. The compressing technique refers to compressing the fragmentary components to deform them.

\subsubsection{Forming Perception}

After a product is formed comes the fourth axial category, Forming Perception, in which the participant has instinctual emotional responses and cognition towards the appearance of the formed product. These categories include Semi-Archetype, Contradiction, Weird, Irony, and Restlessness, with 129 nodes. The number of nodes in every sub-category is shown in detail in Figure 21.

The sub-category Semi-Archetype refers to defining the basic original form of the object with familiar images and shared cognition and includes Reconstructive Archetypes and Borrowed Archetypes. The nodes are named 


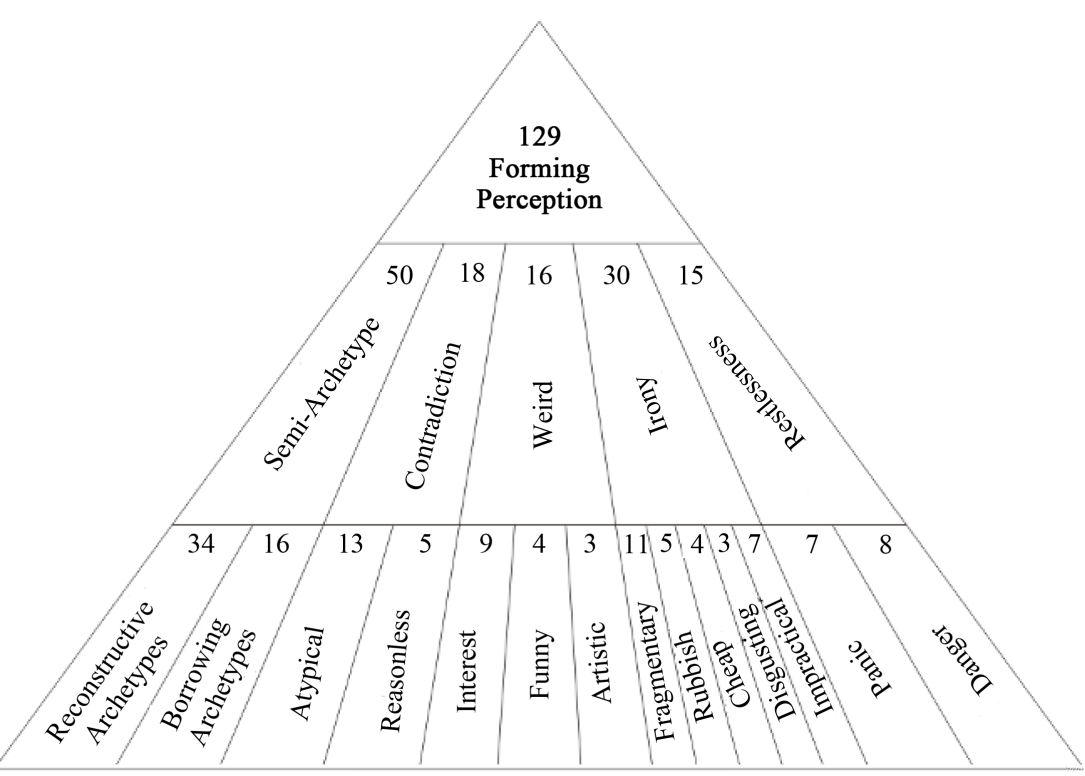

Figure 21. Main categories and sub-categories of Forming Perception factors in readymade design.

in reference to the two concepts in the three archetypes summarized by (Lin \& Cheng, 2004). The former, different from the pure archetype, reconstructs and remolds the product by revising, duplicating, and disassembling the single archetype and then presents the product in a different, unique mold (such as the lamps created by means of the shape of the light). The latter (second) strengthens the concept of the archetype by borrowing the shape of the object (such as the lamp shade-inverted funnel). The object and archetype exhibit the same features in a certain form and can be compared with each other. The sub-category contradiction refers to the combination of illogical, extreme, contrasting and conflicting components and includes Atypical and Reasonless. This subcategory is totally different from the traditional image in that it overturns the established thinking and cognition of the participant. This type of perception usually appears in surreal works of art, such as Meret Oppenheim's Object, which uses a fur-covered teacup to produce contradiction in functions (Willy, 1975). The sub-category Weird refers to presenting the appearance of a product in interesting, exaggerated, humorous, unexpected and creative art forms, which makes the participant feel innovative and interesting. This sub-category includes three nodes, namely Interest, Funny, and Artistic. The sub-category Irony, named after one of the ten categories of Droog's works in the book Simply Droog, refers to expressing personal subjective viewpoints in an ironic way (Ramakers, 2006). This sub-category covers five nodes, namely Fragmentary, Rubbish, Cheap, Disgusting, and Impractical, which all look vulgar and valueless and make the participants tend to satirize using critical negative language as a result of the deformed appearance of the recycled objects. The sub-category Restlessness exerts inexplicable feelings of restlessness, such as doubt, on the participants because the materials or operation methods of the components of the products are in contradiction with the things experienced by them in the past. This sub-category includes Panic and Danger.

\subsubsection{Interpreting Meaning}

In the last axial category, Interpreting Meaning, the participant reflects on the previous experience and memory and interprets the deep meaning hidden inside the product, in a series of processes forming and perceiving the products. This category includes four sub-categories, namely Familiar-Not So Familiar, Affection, Experience Comparison, and Reflections on Environmental Protection, with 92 nodes. The number of nodes in every subcategory is shown in detail in Figure 22.

The sub-category Familiar-Not So Familiar refers to linking to people's memories of old things by selecting the old form and function of the products and design with ideas and the free mixture of the product archetype (Ramakers, 2006). This sub-category includes Sense of Familiarity and Story, the former meaning knowing the name of the component or feeling familiar with the component due to viewing in the past and the latter meaning 


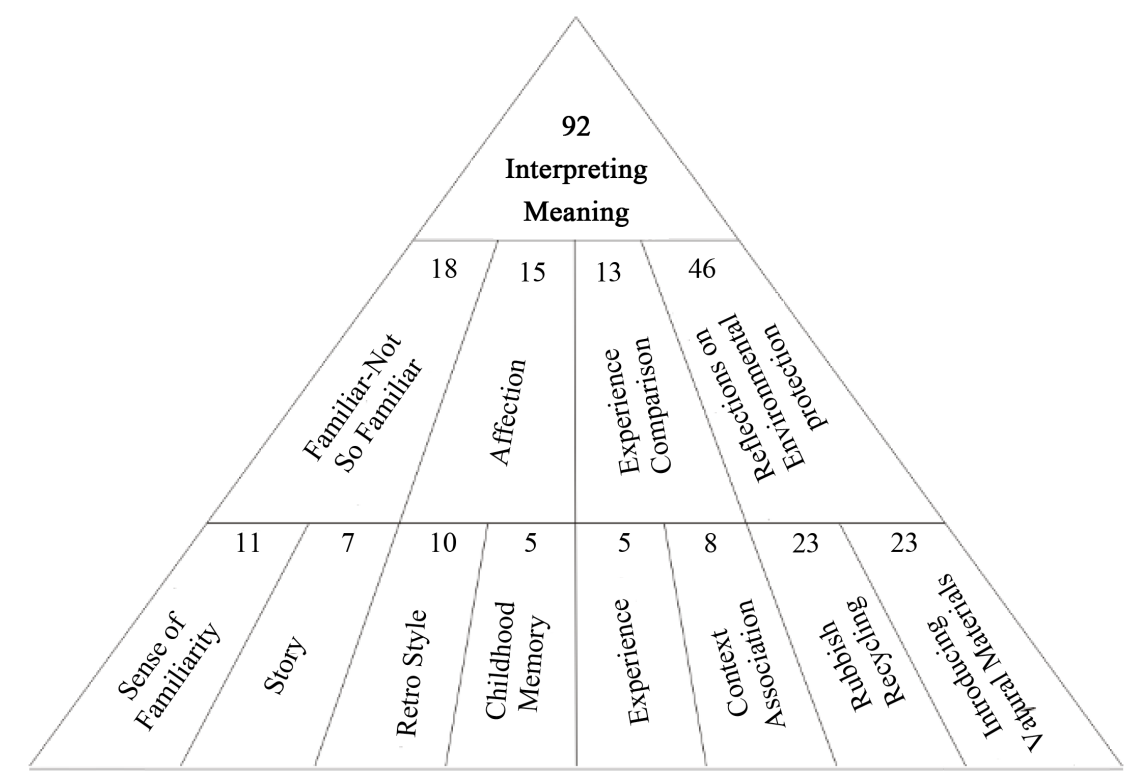

Figure 22. Main categories and sub-categories of Interpreting Meaning factors in readymade design.

triggering the old story and scene related with the component. These concepts coincide with the theory emphasized by Achille that memories can produce a continual sense of coherence for old designs and express a sense of familiarity towards such objects (Erlhoff \& Brandes, 2006; Polano, 2002). The sub-category Affection refers to components with special meanings, such as childhood toys, ancient objects and old commodities, which can make people express affectionate responses of missing and reminiscence. It includes Retro Style and Childhood Memory. The sub-category Experience Comparison includes Use Experience and Context Association, with the former making people compare the products with past use experiences and the latter making people guess the suitable disposition location of the product according to the use place and environment of the components. The sub-category Reflections on Environmental Protection, like the concept Use It Again, is an issue that triggers a reflection on resource recycling (Ramakers, 2006). This sub-category includes Rubbish Recycling and Introducing Natural Materials, which introduce reused industrial waste and products made out of natural things, respectively.

\section{Discussion}

This study examined how people respond to variations in artistic ready-made products and what key features induce in the cognition processes. This study indicates that a stronger variation in mixed components elicits stronger responses within ready-made products. Ready-made products provide participants with perceptions ranging from instincts to deep interpretations. The first stage, Selecting Components, mainly focuses on the selection of substituting product components. The second, Extracting Function from the selected components, consider available Affordance with the feature, size and function of the component as prerequisites and applies it in the product in a skillful way. The third stage, Editing Technique, refers to distinguishing the degree of destruction of the body or component to cater to the structural requirements, including retaining a complete form or destroying form. In the fourth stage, triggers direct the process of Forming Perception following the formation of the products. In the fifth stage, Interpreting Meaning, the deeper meaning and existing value of the products are interpreted. The sensitivity of recognition may depend on participants' level expertise (Lin et al., 2011). Because the professional designers in this study are familiar with ready-made designs, they might be better able to detect the small feature differences between stimuli during the within-category classification task. We consider evidence for these conclusions separately in the following sections.

\subsection{Difference between Participants with and without Design Backgrounds}

Figure 23 shows a comparison between the designers and the novices. In general, designers involve wide di- 


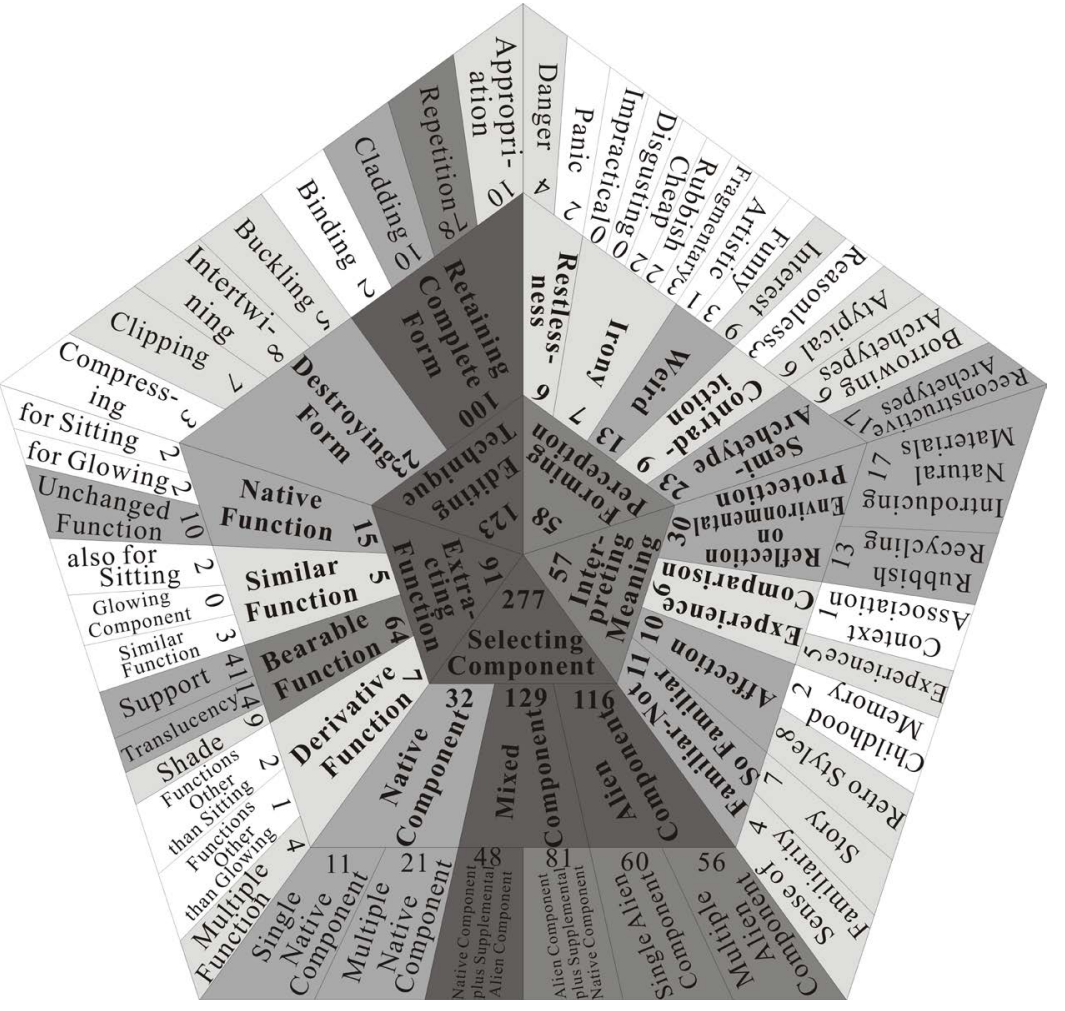

(a)

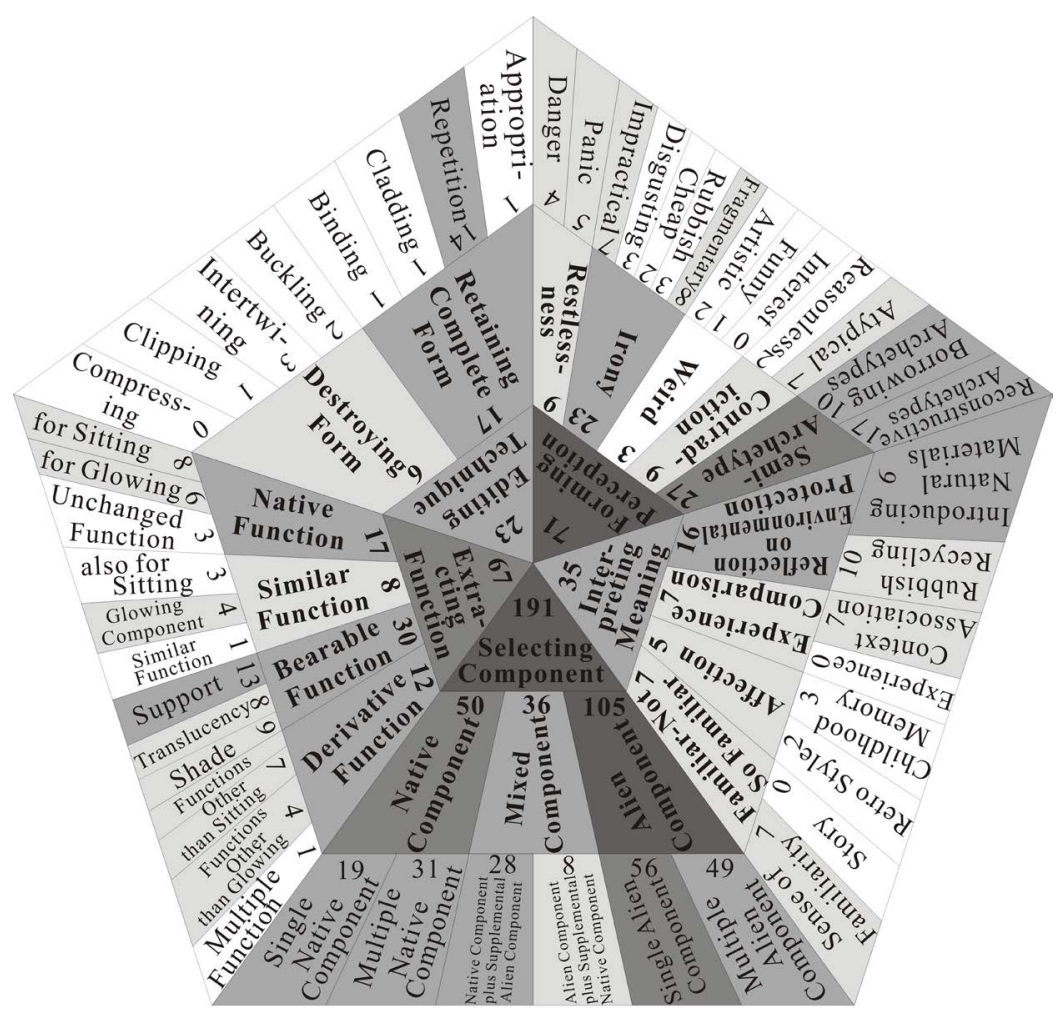

(b)

Figure 23. Distribution diagram of node reference distinguished by participants’ backgrounds: (a) designers and (b) novices (The method of color filling in each block is the same as that in Figure 25). 
mensions, expressing their viewpoints about the ready-made design almost entirely, whereas novices tend to perceive the appearance and rarely mention other concepts.

In the concept Selecting Components, due to the participants' backgrounds, designers have sharper outsight than N (references $277>191$ ). They can judge the differences according to the organization structure of the products in different components, so they can pick the Mixed Components, which are hard to distinguish, from the other two categories. In contrast, novices mostly directly divide the ready-made products into two groups (Native Component and Alien Component), and Mixed Components, which are difficult to distinguish, are selectively classified under the category of Alien Component. As for Editing Technique, designers with product design training are very familiar with all types of design techniques (references $123>23$ ) and can even clearly identify the techniques in the designs of products. Comparatively, novices describe the general design technique.

For example, a designer might think, this is clipped and twisted (sample a24 in Figure 24(a)), whereas a novice can only think, this is usable new product, destroyed or processed to be made like this (sample a02 in Figure 24(b)). As far as Forming Perception is concerned, the emotional responses of the two parties are tremendously different (references $58<71$ ). Designers often come into contact with new things, so they are accustomed to weird designs, feeling not at all strange towards them. They can find the fun in a playful attitude. Some designers even clearly express their fondness for certain types of unique designs in the experiment process. By contrast, researchers find obvious negative emotional responses in novices, who claim that they have never observed such weird things and are even doubtful or criticize some designs, calling them fragmentary or not at all practical.

\subsection{The Ratio of Axial Category Reflects the Degree of Perception}

The five axial categories are sequenced in descending order according to the total number of the sources of the nodes, with the ratios (references $468>158>146>129>92$ ) coinciding with the degree of the participants' perception. From exterior to interior, the perception dimensions of the first three categories mainly target the exterior appearance of the products, and the last two involve the interior subjective response of the subject. The perception ratio is the highest in Selecting Components (references 468) because the obvious borrowed component is easy to detect. It is the second highest in Extracting Function (references 158). The classified samples are product design, so the function is a secondary focus of the classification. The ratio is the third highest in Editing Technique (references 146). After the function is determined, the manifestation technique of the product should be given focus. It is the fourth highest in Forming Perception (references 129). Due to the different strengths of the emotional responses of the participants, some emotions are hidden and not immediately manifested, whereas others are strong. They vary based on individual differences. The perception dimension of Interpreting Meaning

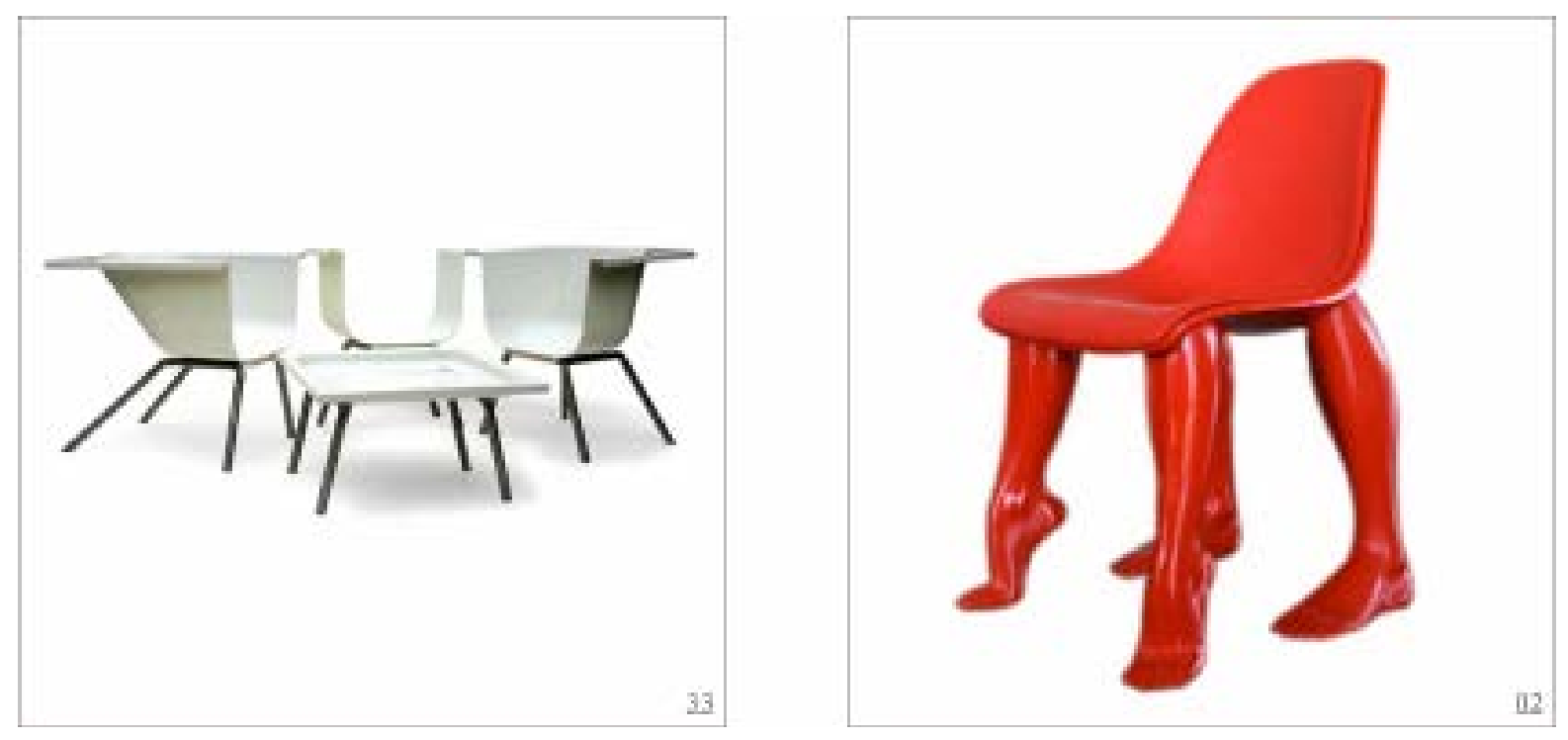

Figure 24. Examples of the differential responses between designers and novices: (a) sample a33 and (b) sample a02. 
(references 92) is the lowest because participants have different understandings of the product and cannot experience the deeper meanings due to a lack of knowledge about the design intention behind the products.

\subsection{The Arrangement Sequence of the Axial Category Coincides with the Creation Procedure}

As has been mentioned previously, the axial categories are arranged according to the degree of perception, and except for this, the previous three items coincide, as well. First, Selecting Components includes the careful choice of materials as a way to determine how to shape a product. Second, Extracting Function includes the choice of functions from the original products that can possibly supply functions. Third, Editing Technique includes molding the components and shaping the products by means of various types of methods. Fourth, Forming Perception and, fifth, Interpreting Meaning correspond to superficial and deep-seated perceptions, respectively. The above creation procedures seem to reflect Constructivism, Functionalism and Post-Modernism. Selecting Components, such as Constructivism, structures the world with the new materials. Extracting Function, such as Functionalism, pays heeds to the economy and practicality of the material use, breaking the traditional shaping rules and using function as the main consideration. Moreover, Editing Technique inherits the cynical attitude of Post-Modernism, pushing people to reflect by scratching up things and skillful concatenation.

\subsection{Product Items are Named Directly after the Borrowed Objects}

The products fall into three forms according to the degree of borrowing of the objects. The larger the proportion of borrowing is, the more the products tend to be alien components. The classification method is directly named after the items of the alien components. For example, for participants classifying the chair made out of a bathtub as a bathtub (Figure 25), is the product category a bathtub or chair? This confusing issue is so interesting that it deserves further attention in future studies.

\section{Conclusion}

This study refers to the creation techniques and design language of designers listed in design literature and assigns them as nodes in the coding guided by grounded theory, linking the relationship between literature exploration and the card worth experiment. Then simple quantification is performed in reference to the node number, so the content in the front coincides with that in the back. There is one prerequisite for this method: only researchers equipped with abundant specialized background knowledge can distinguish useful information from a pile of complex material. More importantly, the general Kansei engineering studies carry out investigations on participants' feeling towards issues by means of adjectives, focusing more on the feeling of the participants. By contrast, this study aims to intentionally analyze the concerned issue in depth, analyzing the relationship between the compositions of the products and the perception. In a future study, the sequence of Axial Coding, particularly as it pertains to the process of creation for ready-made products, will be tested on real creations, and the design workshops are expected to uncover more problems and insights in real creation. For another experiment of ready-made products, thorough investigations should be conducted examining the contradictory responses of participants based on the proportion of borrowed objects.
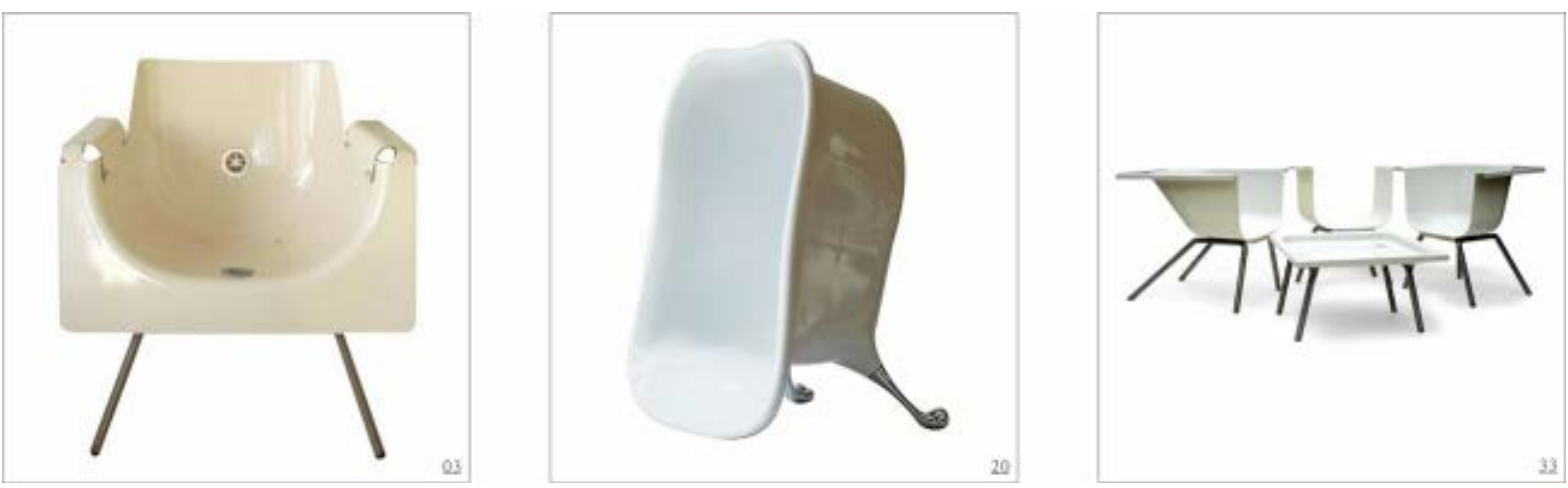

Figure 25. Examples of confusion with classifying product category: samples a03, a20, and a33 are made of the bathtub. 


\section{Acknowledgements}

This research was supported by grants from the National Science Council of Taiwan to Ming-Huang Lin (NSC 100-2221-E-009-089-MY3).

\section{References}

Cheng, S. H., Lin, S. H., \& Lin, M. H. (2010). Operation Follows Meanings: A Case Study on the Lamp Design with Double Metaphors and Motion Semantics. Journal of Design, 15, 1-19.

Erlhoff, M., \& Brandes, U. (2006). Non Intentional Design. Cologne: DAAB Press.

Fang, Y. M., Lin, M. H., \& Liao, J. H. (2006). Perception Patterns of Figurative Expressions and Incongruity-Resolution Theory in Humor Design. Journal of Design, 11, 65-81.

Fernando, C., \& Humberto, C. (2010). Campana Brothers: Complete Works (So Far). New York: Random House Press.

Glaser, B. G., \& Strauss, A. (1967). The Discovery of Grounded Theory. New York: Aldine de Gruyter Press.

Goodman, J., Clarke, S., Langdon, P., \& Clarkson, J. P. (2007). Designers’ Perceptions of Methods of Involving and Understanding Users. International Conference on Universal Access in Human Computer Interaction. Berlin: Springer. Lecture Notes in Computer Science, 4554, 127-136. http://dx.doi.org/10.1007/978-3-540-73279-2_15

Hong, Y. J. (2009). Fernando and Humberto Campana in Brazi: Salvage Floating Objects of Everyday Life into High Design Products. Design Magazine, 145, 29-33.

Hu, Z. F., \& Lin, P. C. (2008). Graphical Symbols: The Effects of Information Loads on Recognition Performance. Unpublished Doctoral Dissertation, Taiwan: National Taipei University of Technology.

Kokotovich, V. (2008). Problem Analysis and Thinking Tools: An Empirical Study of Non-Hierarchical Mind Mapping. Design Studies, 29, 49-69. http://dx.doi.org/10.1016/j.destud.2007.09.001

Lai, I. C. (2004). Framework for Case-Based Reasoning to Support Idea Association in a Brainstorming Session. The Proceedings of 9th CAADRIA Conference, Seoul, 209-222.

Lin, M. H., \& Cheng, S. H. (2004). The Archetypal Theory and Archetypal Design. Journal of Design, 9, 1-16.

Lin, M. H., \& Cheng, S. H. (2008). Analysis of Castiglioni’s Design Aesthetics and Influences. Industrial Design Magazine, 36, 188-193. http://readopac2.ncl.edu.tw/nclJournal/search/detail.jsp?sysId=0006408253\&dtdId=000040\&search_type=detail\&la=ch

Lin, M. H., Wang, C. Y., Cheng, S. K., \& Cheng, S. H. (2011). An Event-Related Potential Study of Semantic Style-Match Judgments of Artistic Furniture. International Journal of Psychophysiology, 82, 188-195. http://dx.doi.org/10.1016/j.ijpsycho.2011.08.007

Luo, K., \& Lin, P. C. (2007). Investigation on the Cognitive Model of High-Brand-Value Identity Design. Journal of Design, 12, 47-68.

Oxman, R. (1994). Precedents in Design: A Computational Model for the Organization of Precedent Knowledge. Design Studies, 15, 141-157. http://dx.doi.org/10.1016/0142-694X(94)90021-3

Oxman, R. (2004). Think-Maps: Teaching Design Thinking in Design Education. Design Studies, 25, 63-91. http://dx.doi.org/10.1016/S0142-694X(03)00033-4

Polano, S. (2002). Achille Castiglioni: Complete Works (Electa Architecture). Milano: Phaidon Press.

Ramakers, R. (2006). Simply Droog: $10+3$ Years of Creating Innovation and Discussion. Amsterdam: Droog.

Rawsthorn, A. (2008). Enzo Mari: A Rebel with an Obsession for Form. http://www.nytimes.com/2008/11/03/style/03iht-design3.1.17414904.html

Strauss, A. (1991). Qualitative Analysis for Social Scientists. Cambridge: Cambridge University Press.

Sudjic, D. (1989). Ron Arad: Restless Furniture. New York: Rizzoli Press.

Taki, Y. (2004). From the Legacy of the Castiglioni Brothers (pp. 127-131). Tokyo: AXIS Inc.

Willy, R. (1975). Objekt-Kunst: Von Duchamp bis zur Gegenwart. Cologne: M. DuMont Schauberg Press.

Wong, J. F. (2010). The Text of Free-Form Architecture: Qualitative Study of the Discourse of Four Architects. Design Studies, 31, 237-267. http://dx.doi.org/10.1016/j.destud.2009.11.002 